Accepted for publication in Social and Cultural Geography on 18 March 2015.

\title{
Time-geography, gentlemen, please: chronotopes of publand in Patrick Hamilton's London trilogy
}

\author{
Philip Howell and David Beckingham \\ Department of Geography, University of Cambridge, Downing Place, Cambridge \\ CB2 3EN, UK
}

\begin{abstract}
This paper considers the time and the place of drinking in modern British life, as represented in Patrick Hamilton's trilogy of novels set in the publand of London's West End in the interwar years, and through Mikhail Bakhtin's concept of the chronotope and with critical nods to Hagerstrand's timegeography corpus. The chronotopes of pubs and their neighbourhoods, which we term 'publand', are discussed initially in their novelistic presentation in Twenty Thousand Streets Under the Sky (1935), and then in relation to the 'character zones' of the novels' principal protagonists. The key themes, defined in the paper are the asynchronicity of personal and social relations, the dialogic construction of heterochronicity, and the presentation of a prosaic chronotope. Though the paper is a contribution to literary geography, we aim to contribute to the cultural geographic understanding of the timespace rhythms and routines of everyday leisure drinking, making claims for the wider significance of chronotopic analysis.
\end{abstract}

Key words: chronotope, time-geography, literary geography, Patrick Hamilton, pubs, drinking.

'Last orders, gentlemen, please!' 'Time, gentlemen, please!' 'Drink up, gentlemen, please!' 'Past time, gentlemen, please!' With this nightly ritual does the law descend on the pubs, always unwelcome, and positively intolerable on Saturday nights. (Gorham 1939/2010: 67)

\section{Introduction}

Resoundingly familiar as well as faintly anachronistic, the barking out of 'last orders' is a very British institution, a hangover of the world the Great War bullied into being. Its prefatory invitation, followed shortly by the peremptory obligation of 'time, please!', serves as a daily reminder that the activity of drinking alcohol in British public houses is limited to licensed premises with restricted hours and conditions of comportment: a distinctive regulation of 'time, place and manner' (Valverde 2003: 149). The resulting landscapes and rhythms of drinking remain relatively neglected, but they are eminently worth revisiting in the light of the spatio-temporal turn, as they help to constitute the 'timespace routines of everydayness' (Mulíček et al. 2014: 2). Leisure drinking is profoundly shaped by such routines and regulations, being spatially and temporally containerized, in the classic terminology of Torsten Hägerstrand's time-geography. To use a rather different language, we can argue that drinking in public is a profoundly chronotopic activity, following Mikhail Bakhtin's influential coupling of time and space as 'an integral way of understanding experience, and a ground for visualizing and representing human life' (Morson and Emerson 1990: 375). It is this formulation that we explore in this paper, aiming to 
endorse the importance of chronotopicity for the prosaic world of the British pub. But we turn to the prosaics of drinking in another sense, invoking Bakhtin's valorisation of literature's encounter with the everyday and the ordinary, his argument for the participation of art within life, and more precisely the role of time/space forms in mediating everyday experience and consciousness as well as literary expression (see Morson and Emerson 1990: 15-36; Painter 2006). As far as literature goes, we make specific reference to the novelistic presentation of pubs and publand in the works of the British writer Patrick Hamilton (1904-1962), and to his semi-autobiographical London trilogy, the three short novels - The Midnight Bell (1929, subsequently MB), The Siege of Pleasure (1932, SP), and The Plains of Cement (1934, PC) - collected in 1935 under the title Twenty Thousand Streets Under the Sky.

Why these novels? For a start, because they are neglected but important literary presentations of the modern city and modern urban life, well worth revisiting. Patrick Hamilton has a distinctive place in the fictional portrayal of London, his being a famously bleak account of the desperation of ordinary lives in the years of economic, social and political crisis either side of the Second World War. He has been called the 'laureate of London's rootless masses' (Branston 2004), 'a genuine minor poet ... of the loneliness, purposelessness, and frustrations of urban contemporary life' (Times 25 September 1962: 15). Twenty Thousand Streets is a biting portrait of working-class London between the wars, centred on the downtrodden inhabitants of one particular district of London's West End, and written with the aid of first-hand knowledge as well as dispiriting personal experience. Michael Holroyd, in the introduction to the 1985 edition, sees Hamilton's trilogy as a 'social map of this malignant city', whilst his biographer affirms that 'he knew his chosen territory and mapped it on the printed page with the assurance of an expert cartographer' (Jones 2008: 4). Less well appreciated, however, is the fact that Hamilton is not just a cartographer but a chronotopographer, concerned with time as well as space. We concentrate on these novels because they offer a remarkable guide to the modern urban chronotope, the patterning of time/space in the real as well as the fictional city.

The role of time in animating the geography of the novels is studiously marked and deserving of explicit elaboration, not least for the light they shine on the temporal and spatial constitution of the world beyond the novel. It is possible, in the narrowest sense, 'to speak of each novel as possessing its own chronotope, its own particular conception of time and space' (Klausner 2012: 48), and we intend here exactly to explore the specific chronotopographic signature of Hamilton's presentation of London between the wars, including the ways in which the novels' emplotment operates through the presentation of spatiotemporal 'character zones'. But we have a wider purpose in this discussion of the novelistic treatment of time, space, and character in Hamilton's work: firstly, to respond to James Lawson's recent call for geographers to place more emphasis on the 'remarkably fresh' concept of the chronotope (2011: 385,386), particularly in mind of Valverde's recent complaint that time and space should not be taken 'as separate dimensions to be considered one after the other' (Valverde 2015: 10); to demonstrate moreover that novels enhance our understanding of the nature of temporality and spatiality in social life (see Lawson 2011: 392; Brosseau 1995); and, finally, to provide a critical commentary on the role and representation of drink and drinking in British society. Although our immediate focus is the literary work, then, we must remind ourselves that the chronotopes of 
drinking are not confined to the textual but rather help structure our experience and understanding of the social world itself.

\section{Bakhtin and the chronotopic imagination}

If the representation of the relation of space to time is one of the central questions for contemporary spatial theory, one of the most promising avenues of exploration is Bakhtin's elusive but essential formulation of the chronotope (see Crang 2001; Holloway and Kneale 2000; Klinke 2013; Valverde 2015). Bakhtin's arguments can be confusing and ambiguous but there is at least a relatively straightforward definition of the chronotope on offer. For Bakhtin begins his canonical discussion by stating that the concept refers to 'the intrinsic connectedness of temporal and spatial relationships that are artistically expressed in literature' (Bakhtin 1981: 85). He maintains that in the novelistic chronotope, time thickens, 'takes on flesh, becomes artistically visible'. As 'the primary means for materializing time in space', chronotopes organize the fundamental narrative events in the novel, making them concrete and substantial (Bakhtin 1981: 250). One simple, basic, but perfectly serviceable initial definition follows: the chronotope is a means of analyzing 'how fictional time, space, and character are constructed in relation to one another' (Vice 1997: 201). In the restricted definition (Holquist 1990: 113) that is indeed our primary concern in this paper, we are enjoined to look at specific literary texts and the work of such representations of space and time. That said, individual texts should also be understood via Bakhtin's project of an historical poetics, for the molding of time and space enters into the development and elaboration of genres. In terms of the analysis of the novel, Bakhtin's extensive historical survey shows how its sub-genres establish distinctive tempo-spatial norms (Collington 2001: 224), 'particular spatiotemporal modes' (Valverde 2015: 10), so that the historically developing presentation of novelistic time and space grounds his discussion of the evolution of the novel and its distinctive genres (Bakhtin, 1981; Bakhtin, 1984: 101-180).

To complicate matters, the concept of the chronotope must further be approached through Bakhtin's wider discussion of narrative and literary form. His conception of time/space was developed in conjunction with his linguistic/philosophical analysis of what he terms heteroglossia ('other people's words': that is, the differentiation of all 'language' resulting from the necessary social and historical heterogeneity of actual speech acts or 'utterances'), and to his related analysis of dialogism (the 'doublevoiced discourse' that organizes this heteroglossia without erasing its essential otherness). To summarize very baldly, the words and language that constitute the building blocks of all texts take their meaning from diverse, socially specific, geographically situated and historically inherited utterances, always unauthorized and alien to the writer herself or himself. These performed speech acts are necessarily dialogic - being shared, social, situated, and culturally specific encounters made possible by the generalised systems of language inherited from the past, and its forms and norms. In the relentlessly relational perspective captured by the term dialogism there is no dyadic separation between speech and language, nor between individual and society, or self and other, but instead a saturation of 'the different degrees each possesses of each other's otherness' (emphasis in original, Holquist 1990: 51) in all identities and forms of expression. As far as writing is concerned, this means that all prose literature at least, and most certainly novels, betray and glory in what Bakhtin 
describes as 'dialogic agitation'. In a less-quoted, but admirably straightforward formulation, Bakhtin states that '[i]n all areas of life and ideological activity, our speech is filled to overflowing with other people's words, which are transmitted with highly varied degrees of accuracy and impartiality' (Bakhtin 1981: 337). For Bakhtin, the general linguistic condition of heteroglossia becomes instantiated and 'dialogized' in the form of the novel (above all other genres).

Now the chronotope concept has a somewhat ambiguous relationship to both heteroglossia and dialogism, but chronotopes in the novel clearly bear out the multiple, socially and historically differentiated worlds or viewpoints always already articulated because of the heteroglot nature of language itself, and which necessarily act to establish dialogic relationships within any given text. Here we have at least one plausible link to heteroglossia and dialogism, for insofar as all utterance represents specific 'points of view' or focalizations - up to and including worldviews and ideological positions - and necessarily incorporates the time/space categories of 'the other', heteroglossia enters into a dialogical relationship with both specific and generic novelistic chronotopes. Chronotopes as a conception direct us to understand the role that time/space plays in the operation of literary works, genres and forms, so that (in Bakhtin's terms) the centripetal work of representation - the specific creation of the world or worlds within the text - cannot be divorced from the centrifugal forces that govern a text's creation, circulation, reception, adaptation and evaluation, its essential otherness. Literature is indeed but one instance of 'the Manichaean opposition' exhibited in all utterances, the dialogue 'between centrifugal forces that seek to keep things apart, and centripetal forces that work to make things cohere' (Holquist 1990: 69; see also Reed 2014: 9).

At the risk of labouring this theoretical introduction, it is worth restating the point that to speak of chronotopes is to draw attention to the particular conditions and forms of utterances in both novelistic and 'real-world' time-space. It has to be underlined that chronotopic analysis can never be confined to the textual realm, for changes in the chronotopic organization of real life feed back into and help to condition the nature of fictional representation: the chronotope is 'a formal matrix of representations of time and space that underlies both literary genres and sociocultural expectations and awareness' (Reed 2014: 82). Chronotopes refer to the ways in which space and time are always bound together, as well as to the particular forms in which such conjoined space-time is engendered, experienced, and ordered in historically and geographically differentiated social life. In this regard, Bakhtin defines as a 'specific chronotope', 'a specific form for experiencing time and a specific relationship between time and the spatial world' (Bakhtin 1981: 205). In the very widest sense, the emphasis on dialogism captures the interaction between speaking subjects, the encounter between texts and the world, and between authors and characters and readers, all of which involve complex relationships between chronotopes. Linking the chronotopes of narrative or representation with the chronotopes of the 'real-world' is admittedly fraught with difficulty. James Lawson (2011) has, for instance, recently explored this problem of the 'bridge' linking the space-times of the real world to those of fictions, principally by way of a certain simplification, noting that narratives in general produce spatio-temporal truth claims, and by considering the relationships that nonfictional narratives have to their chronotopes, and thus at least indirectly to reality itself. Lawson adds, problematically, that 'with histories or realist novels, this relationship is one of strict correspondence' (Lawson 2011: 385), so that 'realist 
novels are "meant to rest on real-world chronotopes, both through the limits of the author's imagination and through the willingness of audiences to suspend disbelief' (Lawson 2011: 396). There is some truth in this observation - readers' responses to texts have to correspond chronotopically in some sense in order for such a reality effect to work - but we must be aware just how complex is this production of 'realistic' chronotopes. For one thing, any bridge between real-world chronotopes and fictional ones is never only one way, for novelistic chronotopes have a notable capacity to install themselves in the real world (as, for instance, the phenomenon of 'Bloomsday' shows). Moreover, it is never a question of calibrating novelistic chronotopes with regard to 'real' ones: for we have to interrogate the unspoken assumptions about the temporal and spatial coordinates of world experience that Holquist (1990: 142) refers to as the 'chronotopic unconscious'. Holquist (1990: 116) points to the impossibility, in Bakhtin's dialogic philosophy, of separating event from interpretation, plot from narration, and the 'givenness' of language or discourse from the 'making' involved in actual speech or utterance. There is always, already, a mediation between what happens and its situation in time and space, such that 'the means by which any presumed plot deforms any particular story will depend not only on formal ("made") features in a given text, but also on generally held conceptions of how time and space relate to each other in a particular culture at a particular time ("given" features)' (Holquist 1990, 116). Or, as Stuart Allan writes, '[i]t is only in and through the chronotope that the "world that creates the text" may be distinguished from the "world represented in the text"" (Allan 1994: 209), adding that the resulting 'dialogic process of exchange between the text and the "historically developing social world" may be characterized as chronotopic' (Allan 1994: 210).

\section{Chronotopes of publand in Twenty Thousand Streets Under the Sky}

For all these theoretical complexities, the utility of the concept of the chronotope in revealing the temporalisation of space within the novel can readily be acknowledged (see for instance Keunen 2001, Liu 1998). In the most straightforward sense, as we have indicated, the analysis of chronotopes pertains to the identification of generic spatio-temporal organising features in literature: chronotopes are 'a type of literary indicator or motif which assimilates temporal issues and spatial relations into an interdependent matrix that itself becomes a narrative centre around which meaning is created' (Liu 1998: 243). We want now to affirm the public house as one such centre, a specific chronotope that delimits the field of narrative possibilities (Klinke 2013: 680) - although we need to quickly acknowledge that 'setting' and 'context' are too static and straightforward terms for the temporal function of the principal novelistic locales. The pub is, arguably, both a centripetal 'domain' and a centrifugal 'site', to use Reed's (2014) recent terminology. But the wider point is that '[s]pace is less the already existing setting for such stories, than the production of space through narrative' (Miller 1995: 7, cited by Crang 2001: 194), so that we should think of this novelistic topography as an active process and practice of narration, rather than a simple referent to a 'real-world' equivalent. Since '[s]ocial localities are not a neutral, passive background of action but on the contrary determine its chronotopic form' (Steinby 2013: 120), we can recognize immediately that the pub (as a workplace and a site of leisure) is indeed far more than a time-space anchor or station, to nod once more to Torsten Hägerstrand's time-geography terms by way of comparison and calibration. We argue specifically that the pub is central to the chronotopography of 
Hamilton's representation of interwar London. The name of the public house that lends its name to the first novel in the sequence, The Midnight Bell, is itself a chronotope, which with its regularised demarcation and diurnal rhythms, establishes both the where and the when of the plot.

Our introduction to the world of this first novel is through the wakening consciousness of Bob, the waiter who lives and works at the Bell, this unremarkable London pub in the district now known as 'Fitzrovia'. Bob is recovering from a hangover-induced afternoon nap, for him an unusual and indeed unnatural occurrence: '[o]nly at dawn should a man awake from excess - at dawn agleam with red and sorrowful resolve. The late, dark afternoon, with an evening's toil ahead, affords no such palliation' (MB: 12). Bob's reflections, or rather the narrator's, or better still, the dialogic 'other' voice of a received wisdom condensed into near aphorism, nods straightaway to a time and a universe out of joint, but this haziness is quickly supplanted by the need to open up the pub for its evening hours of 5-10 pm. We are thus simultaneously placed in the world and in the temporality of work, put under the sign of the clock - albeit one that is deliberately set five minutes fast to ensure the staff being 'on time', a sneaky bit of manipulation characteristic of the time-thrifty employer. Like the clock, the novel is in fact a little ahead of itself. It is as if we are born into the 'pitch-dark and irrevocable Universe' (MB: 12) of the novel, jarringly wrenched from Bob's inchoate dreams of exotic adventure to a benighted and becalmed late October afternoon in London, from the smooth space of the oneiric ocean, if we can appropriate the terms of Deleuze and Guattari (2004), to the striated space of workaday reality.

At 5pm, then, the doors of the Midnight Bell and its neighbouring pubs are thrown open - ' $[\mathrm{t}]$ he bolts on the inner side of the doors of the public-houses are slid back, and any member of the public is at liberty to buy a drink' (PC: 333). The process of opening up, as we are shown in the last novel of the sequence, fleshes out the chronotope of the public house by acknowledging the legal demarcation of when and where the thirsty Londoner is allowed to drink. This is oddly arbitrary, for a kilometre to the south, on the further shore of Oxford Street, 'by a curious construction of the law' (PC: 333) the public houses have to wait until 5.30pm to open; this period of time separates in space 'an arid from a flowing land' (PC: 333; see Gorham 1939/2010: 76). We recognise here not just the 'thisness' of personal experience, but also, following Hägerstrand's (1982) conception of 'diorama' what Mike Crang has termed 'the "thereness" of rules and regulations' (Crang 2001: 193). That said, the novel's narrator tells us that these restrictions, arbitrary or otherwise, are hardly a major hindrance to the city's drinkers, for '[i]n most cases advantage is not at once taken of this liberty. Indeed, it may be said that only the chronically dissolute are instantaneously alive to the opportunity; and the places generally remain gloomy and empty for at least a quarter of an hour' (PC: 333). This observation gestures not only to the legal proscriptions, but also the grudging respect accorded to these rules by the drinkers themselves, thirsty as they are, such discretion being a form of thereness 'present in the landscape as much as the things we can see and touch' (Hägerstrand 1982: 326). The pub's regular customers, whilst the law says that they can now drink, simply have the good sense not to enter the pub too early. In the Midnight Bell these regulars - Mr. Sounder (the inveterate letter-writer), Mr. Wall (something in motors), Mr. Loame (the actor), and Mr. MacDonald (the 'Illegal Operation', or abortionist by 
repute) - drop in one by one, to take up the unending round of pointless conviviality in their preferred section of the pub:

What poor, ranting fools they all were - Sounder, and Loame, and Mr. Wall and the Illegal Operation, and all the crew of bowler-hatted gossips along the bar, and all the valiant couples and trios in the lounge, hatching schemes, discussing events, and summoning the waiter with deep-chested and haughty nonchalance (MB: 121).

At the risk of redundancy, but wanting to nod to the word 'toper' as slang for habitual drinkers or drunkards, we cannot resist calling these 'regulars' chronotopers. In our usage they are defined by the time and place of their 'local', their conversation and manner fixed by a curious mix of licensed opening hours, social norms, and the microgeography of the pub (Kneale 1999). The regulars are all men - 'time, gentlemen, please' sounds its gender specificity quite loud and clear. Women's status in pubs was reflected in their drinking companions, the time of day they drank, the drinks they ordered, and even the rooms of the pub in which they drank (Beckingham 2012: 660; Langhamer 2000: 154; Langhamer 2003; Moss 2009: 109). Indeed, the only women who stay any length of time in Twenty Thousand Streets are workers the barmaid Ella, or the prostitute Jenny and her associates, who should be long gone by closing time. Gutzke (2014: 52) has suggested that the rise in women using pubs in the Second World War was largely temporary, with the trade unable to challenge the social trends 'urging women to return home to marriage, family and children'. Women certainly drink with freedom and regularity in Patrick Hamilton's wartime novel Slaves of Solitude (1947), though the social constraints on women's access to pubs, particularly single women, may well have been looser in London (Langhamer 2000: 73). Nevertheless, for its male habitués, the Bell has a personal, almost familial, atmosphere - at least for that indeterminate period before the arrival of the drinking masses makes it a truly 'public' house (MB: 68). Only at this point does the pub become a fully 'dialogical landscape', with social heteroglossia replacing the tedious familiarity of the regulars' conversation:

It was nearly always so - "The Midnight Bell," at a certain instant of the evening, becoming uncommonly like an accident which had just occurred, and upon whose scene people materialized from/ nowhere in complete dramatic awareness of the event. (PC: 355-6)

The pub, in fiction as in life, is a locale for social encounters, where the spatial and temporal paths of varied people might cross, potentially collapsing social distance, and possibly in something like the carnivalesque manner (Bakhtin, 1984: 123), albeit in debased and neutered form. The novels' ideal narrator avers, again with a sense of popular wisdom, that 'all manner of people frequent all manner of public houses' (PC: 334), and that pubs are thus akin to railway stations and mad-houses. The neighbourhood later to be called 'Fitzrovia', with its characteristic heterogeneity, may be specially marked in this regard: as Bob's co-worker, the barmaid Ella notes, with neither curiosity nor complaint, "We get all sorts in here"' (PC: 334). The Bell is thus permeable, come opening time, to the 'stupendous variety of humanity' (PC: 334) to be found in the district. But, on the other hand, the British public house has long policed such dangerously polyvalent encounters through the architectural separation of saloon, lounge, and bar (Goulding, 'Fitzrovian nights' and 'Locating and being'). With its pretensions to gentility and respectability, the Bell is particularly well provided for in this respect, with not only a Saloon Bar and a Saloon Lounge, but also a Public and a Private Bar. The 'long-established social stratification' (Gorham, 
1939/2010: 62) of the pub is protected through the strict separation of more genteel customers in the Saloon, including women, and the deliberate exclusion of rough and unrespectable others: "Not this side, please!" (MB: 29). Pubs may thus be "palaces of transience' (Jones 2008: 6), but the name of 'regular' attests to the fact that the chronotope of 'the local' is established by routines and rhythms as much as by the unpredictable encounter (Jennings 2011: 204). Take the blowhard Mr. Sounder: 'He generally arrived at about this time, and he would stay, if he was lucky, until closing time. But if he was unlucky, and no one came in to pay his expenses, he would go out and come in again at half-past nine. His first beer was in the nature of an investment' (MB: 21). At the end of the day, with last orders coming at 10 o'clock, there is only the hazy realisation that whatever pleasure was promised has merely been deferred until the morrow. When the pub's 'deceitful clock', and the barman's cry of "“All out!"' (MB: 41) begins the prolonged struggle to expel the lingering drinkers, this imperative is interpreted by patrons as an assault on their happiness, for they were 'only just beginning to enjoy themselves' (MB: 43).

In sum, in Hamilton's fiction the pub and its neighbourhood are marked as distinctive dialogical landscapes (Folch-Serra 1990) and chronotopes. The Midnight Bell is our locus, but it is only one of the 'hundreds and hundreds' of taverns in the area (PC: 333). The chronotopic imagination on offer here is not just of a particular pub, we want to stress, but of a 'publand' more generally. As Maurice Gorham, in his elegy to the pre-WWII London pub, puts it, every one of the four thousand pubs in London on the eve of the Second World War is somebody's local: 'Every one has its regular customers, who use it for some reason in preference to other pubs (for in Central London nobody can be very far from two pubs at least': Gorham 1939/2010: 15). Hamilton's novels are specific, then, but they gesture towards this everyday, prosaic, world: the Midnight Bell could be any pub, any 'local' with its 'regulars'. 'Local' here registers both a locale and its displacement (Axel, 2001: 171). In one of the very few critical discussions of Hamilton's work, Widdowson complains that the novel is a failure because the Midnight Bell is merely 'punctiliously observed' in utilitarian prose (1978: 123). But this is surely misconceived: where Widdowson sees only 'diffusion of effect' (1978: 127) in having such detailed descriptions of physical location, Hamilton's metonymic accuracy does not play second fiddle to a metaphoric symbolism so much as build up a recognisable locale that can be reproduced almost ad infinitum across the metropolis. We do not need to invoke specific pubs as having causal capacities so much as the fact that pubs and other drinking environments are, quite precisely, everyday spaces, 'local' and ubiquitous, that in their very interchangeability construct neighbourhoods, like 'Fitzrovia' and its 'dominant subculture of drinking' (Goulding, 'Fitzrovian Nights') as 'alcohol assemblages'. The Midnight Bell is somewhere, but as a 'temporalised place' (Crang, 2001: 190) it could be (almost) anywhere. Its little world is a generic stage on which its characters exercise their constrained and compromised agency, but the pub and its neighbours are recognisably part of our world, not merely Hamilton's monologic imagination.

\section{Character zones and chronotopography in Twenty Thousand Streets Under the Sky}

What then of the chronotopes pertaining less to the 'setting' as to the business of emplotment and characterization? Attention to character, for so long a kind of 
embarrassment in literary criticism, has undergone a distinct revival in recent years. We would simply affirm the view of characters as participants in a storyworld, participants whose 'characters' and even their thoughts are accessible to readers through our interpretation of their actions and those of other characters as they take place in the possible world of the narrative. There has admittedly been a tendency to privilege readers' interest in individual characters, rather than in fictional time or space (Zunshine 2006: 170 fn 10), but we find more convincing Alan Palmer's focus on fictional consciousnesses inseparable from their presumptive environments, which draws heavily upon Bakhtin to emphasise '[t]he dialogic nature of characters' embedded narratives and the nature of the fictional storyworld as a battleground within which the thoughts and actions of individuals contend and clash' (Palmer 2004:152-3). In our own gloss, we would simply state that forms of time-space, or chronotopes, operating both in fictional narratives and in the world of the reader, allow us to make sense of 'character'. And whilst positing alternative time-space constructs in the same literary work may seem on the face of it to push the chronotope conception beyond its limits (Reed 2014: 137), given the privileging of genre, we want to argue that this agonistic attention to socially embedded character is an important element of any novel's dialogism.

In Hamilton's London trilogy we meet three principal characters, in turn: Bob, the waiter, Jenny, the prostitute with whom he becomes infatuated, and Ella, the barmaid at the Midnight Bell, who loves Bob with neither hope nor expectation. Each of these three characters, we argue, has a distinctive chronotopic register that corresponds to what in Bakhtinian terminology are their 'character zones', their spheres of influence within the novel, the scope and reach of their speech and their activity in general; 'impact area' is perhaps closer to the original Russian than 'zones'. 'What is significant about the Hamilton trilogy is the containment of the three protagonists' character zones largely within the restricted neighbourhood we are terming here 'publand', giving unity of place and also of time, and with a certain degree of overlap, co-presence and coincidence. At the same time as the Midnight Bell allows them to be brought together, the three novels show how the social lives of their protagonists is far from synchronized. This, we will argue, constitutes the principal dialogic thematic to Twenty Thousand Streets Under the Sky, and which constitutes the trilogy's decisive chronotopic signature.

Our introduction to Bob, as already noted, is our introduction to the novel and to the fictional world of the Midnight Bell and its environs. When Bob wakes, in the middle of the afternoon, it is to half-remembered dreams of a sea voyage, somewhere off the coast of Spain, 'far, lovely, and momentous' (MB: 11). He dreams, that is, in the entirely classic chronotope of 'adventure time'. But Bob is pulled fully into consciousness by the rumbling of a lorry off the Euston Road, and the recognition that he has only a few minutes to get ready for his evening shift. The promise of adventure time is violently shunted aside by the prosaic spatio-temporal register of work and routine. This is echoed later on at Hampstead Heath, where Bob takes Jenny for an excursion and escape from the city, an all too brief idyll. Jenny, in the conventional and polite language of romance, and merely for something to say, wishes she had a boat to sail away in, and Bob asks her "'Oh - where'd you sail to?",' as he leads her in the direction of a hostelry called, as if in echo, The Spaniards (MB: 108). Jenny speaks of Romance and highwaymen, driving home the exhausted tropes of adventure 
time, but this quantum narrative annex, temporarily disrupting the novel's chronotope (Keen 2005) merely points up the hopelessness and lack of romance in their situation.

Bob's chronotopic theme is that of routine, therefore, and even his leisure time is safely containerized. London offers itself to Bob, on his afternoons or days off, as a characteristically constrained hunting ground for happiness (Jones 2008: 386) - the 'vast disporting-place of his own soul' (MB: 48) is how the narrator puts it, giving at the same time a sense of Bob's openness to the world and an ironic commentary on its limitations. This world spreads itself to him with the promise: 'London! It was halfpast five and he knew the dusky hour well. It was the hour when London glistened when the lights came forth - when people were going home - when pleasure was just beginning' (MB: 209). But these pleasures are of a particularly limited kind - small pleasures in small measures - particularly when we remember that the evening ends for most with promised pleasure still barely begun. Bob's regular walks emphasise these spatio-temporal constraints. For instance, on Thursday, his day off, at least from $3 \mathrm{pm}$, we are told that Bob spends his few leisure hours 'knocking about the West End', in a routine no less regular for involving tiny and unimportant variations: say, 'Regent's Park, tea in the West End, a visit to the Capitol or Plaza, dinner at Lyons' Corner House, a walk, and home' (MB: 44); or, 'first of all into Regent's Park by the South entrance, and then up and all along by the Zoological Gardens, and at last out again by Camden Town. And then he went down Mount Street, and took it to tea with him at a small and crowded Lyons in the Hampstead Road' (MB: 47).

Bob's routine is disrupted by his encounter with Jenny, who, despite his best efforts, will never be incorporated in this chronotope of leisure and the straight life path of romantic expectation. Bob makes strenuous efforts to anchor his meetings with Jenny, with the Green Man opposite Great Portland Street station their regular, pre-arranged meeting place. But Jenny is utterly unable to synchronise herself with Bob and his world - "II promise on my Mother's Grave," said Jenny, "that I'll meet you at 2.30."/ "Three-thirty! Three-thirty!"' (MB: 150). These missed appointments are abortive time geographies (and Hägerstrand's conception of 'unavailability' hardly begins to cover it) - a signal failure of bodies, spaces and times, but also desires, affects, and interests, to align. Bob is reduced to being a waiter, in emplotment as well as employment. More importantly, Jenny is a streetwalker, and the streets and pubs of 'publand' are, at the same time, her workplace. 'Publand' here we consider closely analogous to the sensual or erotic topography that Tracy Davis (1991) discusses via her conception of 'theatreland': not just the theatres themselves, that is, but also the expectations aroused by their unconfined semiotic influence and the overlapping zones of legitimate leisure and sex work. The chronotopography of drinking overlaps or coincides with that of prostitution, though their maps and timetables are not reducible one to the other. As if to make the point that leisure and work do not synchronise exactly, in The Midnight Bell Bob is brought to the sad recourse of looking for Jenny whilst pretending to be merely strolling for fun: 'Round and round again, down Wardour Street, round by the Corner House, up Rupert Street, round by the Pavilion, and back to Wardour Street again' (MB: 101). These are Jenny's professional haunts, her working rounds, and it is not by chance that Bob eventually spots her on Wardour Street - 'the principal resort of the women of the town' (MB: 49) - not chance at least in sense of the wholesale contingency characteristic of the adventure-time chronotope: 
There is, of course, no sharp dividing line between a man, indolently, throwing himself open to accident, and a man, wearily, hunting round and round for the object of his adoration. And one who throws himself open to accident, in a confined and specific region, with continued zest, between the hours of five thirty and seven, and never dreams of going to the pictures, is difficult to classify. (MB: 161)

Bob and Jenny's sad career - the utter inability to connect, coincide, synchronise - is confirmed by his visit to Jenny's lodgings, and the realisation that his time and her time are quite incompatible: 'a little clock on the mantelpiece, which, after brief debate, and comparison with harlots' wrist-watches, was ascertained to be Right, and which informed Bob that he was due at "The Midnight Bell" in twenty minutes' (MB: 181). And it culminates with their abortive attempt to escape the city for a holiday in Brighton, and the desperate arrangement for them to meet, first at Brighton railway station - "But what part of Brighton Station? Is there a clock?"/ "Yes. Meet me under the clock."/ "But is there a clock?"/ "Well, there must be."/ "Oh, Jenny, you'll drive me mad!" (MB: 202) - and ultimately the fateful, futile arrangement to meet under the clock at Victoria Station. We can, in part in homage to Hägerstrand's Euclidean imagination and in part in the spirit of parody, map Bob's time-geography after being stood up by Jenny for the last time (Figure 1). We should put the stress on critique, perhaps, for Hägerstrand's time-geography is in the end quite impossible to reconcile with the Einsteinian relativity and perspectivism that underwrites Bakhtin's chronotopic imagination. The key recognition is that the 'projects' that characterize the more positivist incarnations of time-geography can be shown, in the 'obsessively drink-laden' atmosphere (Widdowson, 1978: 118) of Hamilton's novels, illconceived, imprudent and ultimately abortive, such that the ellipses caused by drink and disappointment are etched into sharper relief than the lines of conscious decisionmaking. To put it another way, there is precious little rationality in Bob's actions, let alone phronesis (Sui, 2012).

Figure 1: 'Patrick Hamilton, The Midnight Bell: Bob's bender' 


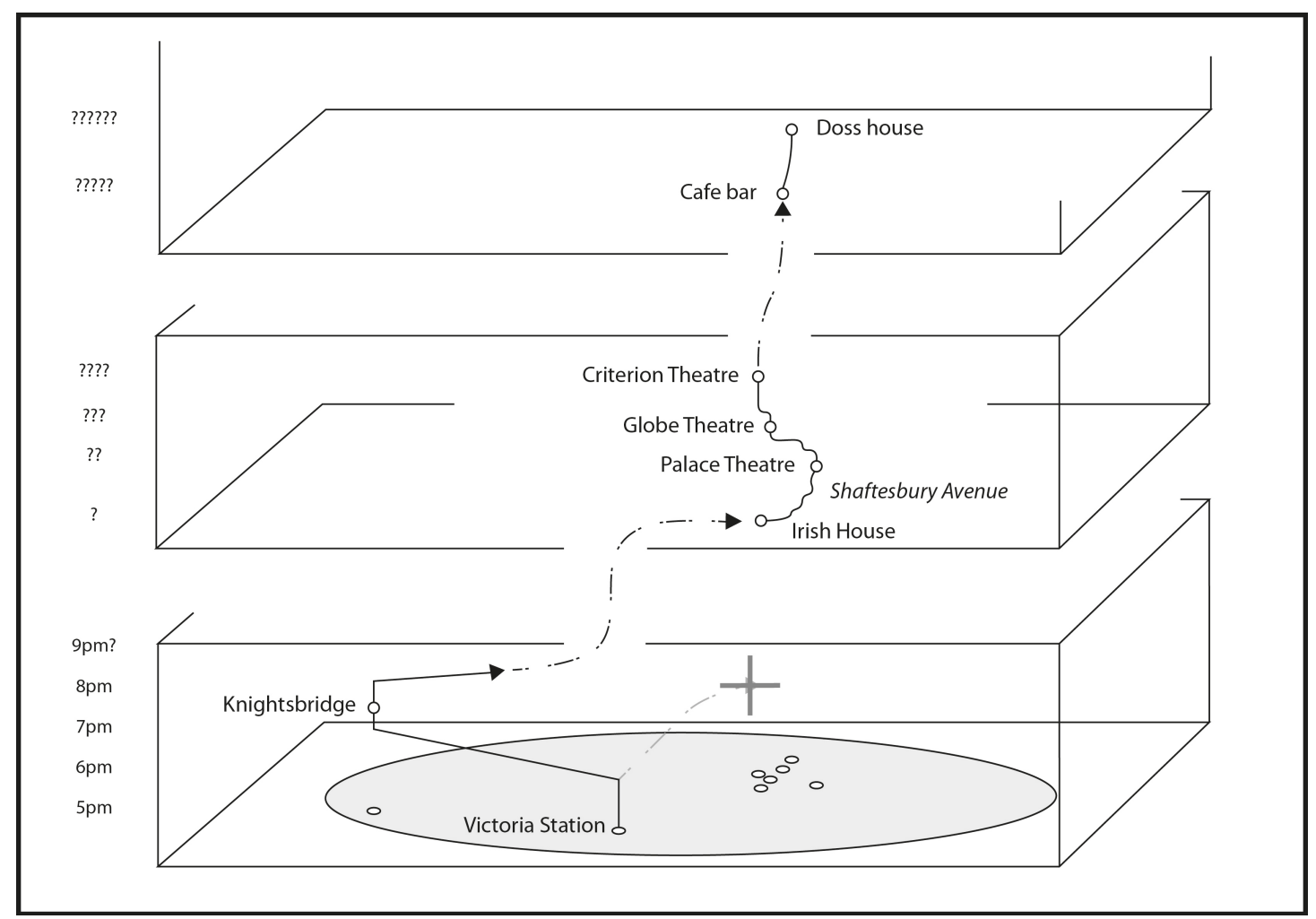

In The Siege of Pleasure we get, again through the use of free indirect discourse, Jenny's point of view as a sequel. Hers is a downfall story, albeit one that parodies and critiques the classic Victorian moralism inherent in the question of how a young woman might become a prostitute, and the chronotopic imaginary of such a 'fall'. We meet Jenny tracing a different kind of time-geography, going round and round in search of customers, and a particularly diffident potential client at that; she attempts to synchronise and coincide with this john, giving him the best chance to see her and make up his mind: 'she was walking regularly and methodically round the London Pavilion: at one moment she was in Shaftesbury Avenue, at the next she was in Piccadilly Circus, at the next in Great Windmill Street, and then in Shaftesbury Avenue again, and so on round', while he dodged about, sometimes 'lurking behind her', other times 'pretending not to notice her' or even looking squarely at her 'as though he had never seen her in his life before' (SP: 223).

This is merely a preamble to the narration of how Jenny came to be a streetwalker. Once again, the public house is the setting, but in this case as a 'haunt of destruction', however heavily ironised. Jenny, fresh from starting work as a maid to two middleclass spinsters in Chiswick, finds herself in a 'large and respectable' house in King Street, Hammersmith, "All got up historical"” (SP: 244, 266), drinking port with her friend Violet and the men they have only just picked up. Jenny has two immediate temporal concerns - the arrangement to see her suitor and soi-disant boyfriend, Tom, and, latterly, the need to get back home and be ready for work in Chiswick the next morning. The first appointment goes by the board, as Jenny is first chastised by the clock, and then resistant to its demands on her and her life: 
She had her eye on the clock in the distance over the bar. It pointed now, to five to eight. If she left at eight o'clock she would have good time to catch a 'bus and reach Camden Town in time for Tom at half-past eight...

Looking at the clock again, she saw that it was two minutes past eight - time she finished up her port and went. Though, of course, she could easily wait until five past, or ten past, if it came to that. Strictly speaking she could make it easily in twenty minutes; she had only said she must go at eight o'clock in order to get away...

It was now five past eight. She would leave at twenty past. She reckoned that that would make her only five minutes late for Tom at the most...

She glanced at the clock again, and saw that it was half past. By rights she should be with him at this moment. (SP: 268-280)

The fuggy Saloon Lounge - and the port - and her new friends - and the dissatisfaction with her life - all make her loth to move, until the pub finally barks out is last orders: 'Now then, gentlemen, please! Time please, ladies and gennelmen! ALL OUT THERE!' (SP: 295).

As it happens, Jenny does not make it to her own lodgings. After an evening of drinking and a night of disaster, she wakes up in the bed of the 'gentleman' she went home with, waking with the greatest anxieties over what had happened the night before and how she might get to Chiswick in time to be saved. The gentleman she has picked up has no concern for time, however, and has thoughts only for breakfast and a leisurely bath, a disregard for the demands of time entirely appropriate to his class. This Mr. Perry, the owner of a sports car, the very instrument of speed, is at the same time 'an idler without knowledge of the laws governing workers' (SP: 320). And this refusal to keep time begins to infect Jenny, who lets her job, her boyfriend, and her respectable chronotopicity slide. Jenny's downfall - or perhaps we should call this the making of her - begins with her missing an appointment, but puts her on the path where she hooks up with, picks up, men in the streets. Chronotopically, she is the odd one out, out of Hamilton's three protagonists, the one who demonstrates 'an utter lack of harmony with her environment' (SP: 329). She is, after all her traumas about the demands of the clock, and of others, the one who is waited on, rather than who waits (for men, for prospective husbands, for proposals, rings and protection). Having thrown in her life as a maid, now she could idle, and 'Those two old fossils could wait for her!' (SP: 323). At the end of the novel, her pick-up, Andy, the one who circled her, erratically at the beginning of the novel, and whom Jenny has to reel in, is the one who has to hurry off, to his work and his wife (SP: 330-32).

What of Ella, last of all? Since the time-scale of Plains of Cement is virtually identical to that of The Midnight Bell we return, after the Jenny interlude, to the chronotope of the pub and of the benighted London that we first encountered with Bob. If Bob and Jenny go their separate ways - Jenny continuing her life on the streets, and if not prosperous or particularly happy, in no obvious sense disappointed with her lot, and Bob, somewhat unconvincingly deciding to go back to the sea, thus achieving something like an entry into the adventure time he dreamt of - there is one character who remains almost entirely stationary. This is the Midnight Bell's unfortunate barmaid, trapped both in unrequited love for Bob, even the prospect of whose absence is traumatic, and also in a working milieu for which she is both entirely suited but which offers her no opportunities for any kind of fulfilled life. Bob's and Ella's narratives barely collide, despite their sharing a workplace and a residence, and the one time they do go out together, when Bob takes her to the pictures, Ella is simultaneously enveloped in the same 'dense, black-brown fog' (PC: 476) that Bob 
rises to in the first book of the trilogy (MB: 90) - we get simultaneity, that is, but not connection. Moreover, Bob's sense of time - 'you only lived once, and not long at that' (MB: 53) - feels all the more like a prison sentence when it comes to Ella. For her, there seems no possibility of escape from the stultifying, ordinary chronotope.

As we have argued, this is in general an economically and socially precarious world which seems to have room for no individual life 'projects' of any substance: no character seems to have much of a plan for the future. But Ella's case is certainly the most abject and pathetic, since her longing for a relationship, and children, is so painfully dependent on chance and opportunity. The only hope she is afforded, given Bob's indifference, is the attention paid to her by the dreadful Mr. Eccles, who offers her some material prospects, but at too high a price given his lamentable qualities as a suitor. Amongst Mr. Eccles's many unattractive qualities, a certain hypocrisy with respect to time stands out. He is a man with military pretensions when it comes to time-keeping, and he tells her in advance of a second meeting to be on time, and that he will only wait five minutes if she decides not to come. But he is late for his first appointment with her - coded, ambiguously, as their first 'date' - and this is characteristic of their difficulties; for if they have less of a problem than Bob and Jenny in coordinating their time geographies, emotionally they are just as out of sync - Ella does not even understand if she should think of these meetings as assignations. It is chronotopically characteristic of Mr. Eccles that he can arrange a 'date' with Ella, but only on the understanding that if she happened to be shopping in the neighbourhood, then they could go on from there. As Ella reflects, wonderingly but also with some bitterness, "he had shown great skill in getting them both into that part of the world purely by accident, so that he did not have to invite her direct, but was merely accommodating her' (PC: 403). Mr. Eccles is the third of the alternative versions of time that structure the novel, the others being Jenny herself, to Bob, incapable of being fixed in time and space, and Mr. Perry, Jenny's gentleman friend, whose idleness and indifference to time displaces her temporal anxieties. Mr. Eccles's rigidities, as well as his double-standards, becomes Ella's chronotopic other, even if he does not in the end become a significant one.

There is also the dialogic incompatibility between Ella and Mr. Eccles to consider. Quite apart from his pompous archaisms, Mr. Eccles sprays interrogatives like machine-gun bullets, whether out of passive-aggressiveness, or, oddly, the performance of amatory reverie. His maddening refrains of 'what?', 'what?' completely defeat Ella's attempts to engage with Mr. Eccles, either to elicit his intentions or to deter his attentions. They frustrate dialogue, of course, but they also demonstrate the 'double-voicedness' of dialogism. Indeed, they are almost a parodic affirmation of what Bakhtin claims as the distinctiveness of novelistic dialogues: 'the mutual nonunderstanding represented by people who speak in different languages' (Bakhtin 1981: 356). Ella herself is not excused from such dialogism and heteroglossia, for sure. As a barmaid, she deals in stock phrases, commonplace saws that count as wisdom for the befuddled drinker, and the regulars who go round the conversational houses with their cant and platitudes. Ella's use of 'expressions sanctified by the ages' (PC: 335) indicates exactly the kind of historicity of utterance that Bakhtin avers, albeit in particularly extreme form. Hamilton gestures to these knots of alien discourse, to condescending as well as humorous effect. But wherever or however they are introduced, the heteroglossia of the ordinary chronotope of publand is amply acknowledged. These dialogic elements help to map out "character 
zones' that are 'formed from the fragments of character speech, from various forms for hidden transmission of someone else's speech, from those invasions into authorial speech of others' expressive indicators (ellipsis, questions, exclamations). Such a character zone is the field of action for a character's voice, encroaching in one way or another upon the author's voice' (Bakhtin 1981: 316). Chronotopes are clearly related to the elaboration of these character zones, for these prosodies and world-views are spatially and temporally located - in the Saloon Bar, above all. Occasionally, albeit riskily and expensively, these character zones are spatially extended, as with the use of the taxi or the telephone or the telegram - expensive to use, undoubtedly flashy, if necessary when time is short and distance too great, but also capable not only of failing to communicate meaning (as with Bob's attempts to telephone Jenny) but also of engendering wholly unanticipated ambiguity (as with Ella's receipt of telegrams rendered into puzzlingly ambiguous poetry by the need for concision). The range of a character's voice is increased, but at the same time distorted and capable of introducing new, and sometimes unintended meanings, just as Bakhtin notes that 'the speech of another, once enclosed in a context, is - no matter how accurately transmitted - always subject to certain semantic changes' (Bakhtin 1981: 340; Lodge, 1990: 79-80).

There is, in short, in the business of plotting, a dialogic and heteroglossic and asynchronic charge to the events of Twenty Thousand Streets Under the Sky, seen through the stories of the three principal actors. In the end, in this multi-temporal or (in Bakhtin's terminology) heterochronous world, these three characters have wholly incompatible temporalities, despite being bound in the same locale and the same unsympathetic Universe. As noted above, they have different trajectories (endings or closures is too emphatic). Bob is off to sea, cycling back to where he began, but with some sense of a line of flight. Jenny, having 'fallen' nevertheless continues to refuse to do the decent chronotopical thing, that is, to repent or to destroy herself. And Ella's experience is apparently only stasis:

If anything had happened to Ella, then, which made her a different Ella to the Ella who had served in the same bar, months back, when Mr. Eccles had not appeared on the scene, and she was calmly living her daily life with Bob as an eternal fixture, it was not observable by the gentlemen, or the Governor, or the Mrs., or any of the staff. (PC: 509)

Nothing it seems had taken place in these 'dull months'. Even in her last meeting with Bob, she cannot escape the demands of punctual rather than personal time: " Is that clock right?" she said. "I mustn't be late" (PC: 506). In such clocktime, we find the 'logic of rationalization' that Franco Moretti sees as pervading 'the very rhythm of the novel', underwriting its 'world of few surprises, fewer adventures, and no miracles at all' (Moretti 2013, 82). For Ella, there is only the end of the day to look forward to, or to dread: 'Then came closing time, and the new man [Bob's replacement], in stentorian tones, amazing in so small a man, began to call "All out!"” (510).

\section{Conclusions}

Hamilton's intended title for the last novel in his sequence was, as it happens, Time, Gentlemen, Please. By unlucky fate, this proved to be already spoken for, and the title was switched to the spatial alternative: The Plains of Cement. This is in one sense equally appropriate, given the general atmosphere of flatness and heaviness that 
adheres to the chronotopes of everyday life for the precarious Londoners that he portrays - a mundane city filled with at best routine and habit, and at worst rootlessness and hopelessness. According to Lawson (2011: 385), chronotopes typically are considered in terms of crisis, catastrophe, and transition for novelistic characters. Bakhtin's discussion of the adventure-time appropriate to some novels of everyday life, or the novelistic chronotope of the provincial town, for example, suggest that mundanity is but a foil to the transformative events that befall their inhabitants. But this contrast between characters and context could hardly be further from Hamilton's portrait of interwar London. Despite being subject to 'wonderful transitions' (MB: 154), the periodic interruptions and 'garish interlude[s]' (MB: 158) of snow or fogs, and the temporary transformations, the grey gaieties effected for high holidays, London seems otherwise devoid of meaningful change for its inhabitants. This is not to say that Hamilton's characters do not display reluctance, resentment, even perhaps resistance, to chronotopic rules and regulations - even if it is by way of a certain foot-dragging recalcitrance. Jenny is the feistiest example of a refusal to follow what we can consider the official chronotopic order. But if it is resistance, it is of a distinctly compromised kind, perhaps merely the pull of an alternative chronotope - contrary rather than any more directly challenging to the social order; and we would still maintain that Hamilton forwards an oppressive present over the hope for individual or social transformation.

This is more than just the realist novel's inevitable penchant for simultaneity and synchrony, metonymy rather than metaphor, for setting and atmosphere and the concrete particulars of space and time, though these surely have a part to play. In Hamilton's brand of realism, his prosaic chronotope, as we would like to call it, we seem to get such attention to routine and daily rhythms that it amounts to something like stasis. In this 'drunken, deracinate [sic] world' (Widdowson 1978: 118) there is precious little becoming, of the kind that Bakhtin observes in the ancient novelistic chronotope of everyday time (Bakhtin 1981: 128). There is no sense either of the conditions of the time, of the impending war, to take an obvious instance. In the dialectic of fixity and flux - being and becoming - that characterizes dialogism and heteroglossia, such chronotopes may be taken to 'precipitate' into everyday settings that more clearly 'fix' social life (Lawson 2011: 389). In part, to wander warily into a discussion of authorial intent, this 'fundamental image of the world' (Keunen 2001: 421) may be attributed to Hamilton's commitment to a Marxism both academic and idiosyncratic, and the deterministic convictions he drew from this monologic official discourse: a chronotope entirely captured, for instance, by the title of the later novel The Slaves of Solitude. Or alternatively we can refer to his personal history of alcoholic depression, whose despair takes such appropriate form - 'Think of the counting of every minute, and the watching of every hour, while waiting for the next coma [sleep], which is so brief and useless!/Is not this a fair description of hell? - one might say eternal hell!' (Jones 2008: 364). Wherever and however dubiously we might claim to find its origin, though, Hamilton's world is clearly more about fixing and being than movement and becoming. Characters in the London trilogy are both stable (they learn little, or nothing) and mostly static in location. His characters do not really change. Jenny does indeed become who she was in some senses always destined to be, like a dingy butterfly emerging from an equally dingy chrysalis - all through accepting a little glass of port! - but this transformation is told in extended flashback; she is, in structural terms at least, literally the same person at the beginning and the end of 'her' excursion into 'adventure-time'. Bob, too, leaps out of social and 
emotional stasis into the fantasy world of adventure, right at the end of his story, but in a surely knowingly unconvincing fashion (a kind of mocking 'and with one leap he was free'). Ella, saddest of all, seems caught in a kind of stasis, behind the bar and behind bars at the same time. In this milieu, spaces and times are neither decisive nor completely contingent but largely habitual, circular, leading nowhere in particular. Given that the standard metaphor for time-geography is that of the dance, this is at best a kind of pavane. The novels seem overall to deny their very 'novelness' - that is, the very openness to the world that Bakhtin so prizes in the greatest practitioners of fictional art, such as his hero Dostoevsky. It is, on the face of it, as if the centripetal powers have scored a decisive victory over the centrifugal forces of heteroglossia, and the monologic over the dialogic.

Now a wider and more layered chronotopic analysis would have to contest this impossibly absolute stasis, and indeed the monologic emphasis on Hamilton's intentions, or his life. Readers' responses and refiguration (the alteration in a reader's consciousness discussed by Ricoeur, 1998), the re-reading and adaptation of works in different media to different effect (Bakhtin's term for this is re-accentuation), the mapping of fiction onto a constantly updated 'real world' - all these phenomena, and indeed many more, necessarily resist this sense of chronotopic closure or stasis, and the supposed self-sufficiency of the literary work. There is not the space here to do more than gesture towards the resultant heterochronicity, which can perhaps be left to another time. But we should at least recognize the limits of determinism, as critics such as Liisa Steinby (2013) have done, in her Bakhtinian affirmation of the ultimate freedom of the acting subject, however chronotopically constrained.It is in this sense that we need to deny with Mike Crang (2001) the self-presence of the everyday - for landscapes no more than languages or people can be said to coincide with themselves - and to recognize in the novel's conflicting chronotopes the virtual dimension of the possible.

All the same, our discussion of the prosaic chronotope of the pub and publand has we hope demonstrated the inseparability of time and space in the tightly constrained fictional landscape of drink and drinking in Hamilton's London trilogy. We hope of course that readers will be directed or redirected to Hamilton's work, which in no small measure adds to the literary imagination of urban life (Alter 2005). We aimed to show how central is the chronotopic imagination to appreciating the novels' (linked) plots and to their revelation of the folding of time and place constitutive of each novel's 'character zones'. As far as literary geography is concerned, attention to the means by which character as well as plot and setting is parlayed in and through chronotopes (indeed, these elements can hardly be separated) is likely to be our central contribution. But, finally, this paper is not intended to be a commentary on fiction alone: in its presentation of the pub and publand, whose chronotopic registers are inherent in the 'real world' as much as in literature, Hamilton's trilogy can also help us, as all good fiction does, 'to grasp the variety of ways in which the relation of people to their world may be understood' (Morson and Emerson 1990: 366).

\section{Acknowledgements}

We would like to thank the comments of the three reviewers who have considered these arguments so knowledgeably and constructively. 


\section{Notes}

1 I am grateful to Olga Petri for taking the time to consider the English translation of the classic essay that is itself better titled as 'Voices in the novel' rather than 'Discourse in the Novel'.

\section{References}

Allan, S. (1994) 'When discourse is torn from reality': Bakhtin and the principle of chronotopicity, Time and Society 3: 193-218.

Alter, R. (2005) Imagined Cities: Urban Experience and the Language of the Novel. New Haven, CT: Yale University Press.

Axel, B.K. (2001) The Nation's Tortured Body: Violence, Representation, and the Formation of a Sikh "Diaspora". Durham, NC: Duke University Press.

Bakhtin, M.M. (1975/1981) The Dialogic Imagination: Four Essays. Translated by C. Emerson and M. Holquist. Austin, TX: University of Texas Press.

Bakhtin, M. (1984) Problems of Dostoevsky's Poetics. Translated by C. Emerson. Minneapolis, MN: Minnesota University Press.

Beckingham, D. (2012) Gender, space and drunkenness: Liverpool's licensed premises, 1860-1914, Annals of the Association of American Geographers 102: 647-666.

Branston, J. (2004) Patrick Hamilton: love and death in publand, The Morning Star 3 November.

Brosseau, M. (1995) The city in textual form: Manhattan Transfer's New York, Cultural Geographies 2: 89-114.

Collington, T. (2001) Space, time and narrative: Bakhtin and Ricoeur, Space and Culture 4, 7-9: 221-231.

Crang, M. (2001) Rhythms of the city: temporalised space and motion, in May, J. and Thrift, N. (eds) TimeSpace: Geographies of Temporality. London: Routledge, pp. 187-207.

Davis, T.C. (1991) Actresses as Working Women: Their Social Identity in Victorian Culture. London: Routledge.

Deleuze, G., and Guattari, F. (2004) A Thousand Plateaus: Capitalism and Schizophrenia. London: Continuum. 
Folch-Serra, M. (1990) Place-voice-space: Mikhail Bakhtin's dialogical landscape, Environment and Planning D: Society and Space 8, 255-274.

Gorham, M. (1939/2010) The Local. Stanbridge, Dorset: Little Toller Books.

Goulding, S. (n.d.) Locating and being in The Midnight Bell: Patrick Hamilton and Fitzrovia, https://www.academia.edu/4175088/Locating_and_Being_in_The_Midnigh t_Bell._Patrick_Hamilton_and_Fitzrovia). Accessed 29 July 2014.

Goulding, S. (n.d.) Fitzrovian nights, (http://www.literarylondon.org/londonjournal/march2006/goulding.html). Accessed 29 July 2014.

Gutke, D. (2014) Women Drinking Out in Britain Since the Early Twentieth Century. Manchester: Manchester University Press.

Hägerstrand, T. (1982) Diorama, path and project, Tijdschrift voor Economische en Sociale Geografie 73: 323-339.

Hamilton, P. (1947/2006) The Slaves of Solitude. London: Constable.

Hamilton, P. (1935/1998) Twenty Thousand Streets Under the Sky. London: Vintage.

Holloway, J., and Kneale, K. (2000) Mikhail Bakhtin: dialogics of space, in Crang, M. and Nigel Thrift, N. (eds), Thinking Space. London: Routledge, pp. 71-88.

Holquist, M. (1990) Dialogism: Bakhtin and His World. London: Routledge.

Jennings, P. (2011) The Local: A History of the English Pub. Stroud: The History Press.

Jones, N. (2008) Through a Glass Darkly: The Life of Patrick Hamilton. London: Black Spring Press.

Keen, S. (2005) Victorian Renovations of the Novel: Narrative Annexes and the Boundaries of Representation. Cambridge: Cambridge University Press.

Keunen, B. (2001) The plurality of chronotopes in the modernist city novel: the case of Manhattan Transfer, English Studies 82: 420-436.

Klausner, N. (2012) The null chronotope and cerebral play in Bely's Petersburg. Available at http://sites.utoronto.ca/tsq/39/tsq39_klausner.pdf. Last accessed 3 February 2015.

Klinke, I. (2013) Chronopolitics: a conceptual matrix, Progress in Human Geography 37: 673-690.

Kneale, J. (1999) A problem of supervision: moral geographies of the nineteenthcentury British public house, Journal of Historical Geography 25: 333-348. 
Langhamer, C. (2003) 'A public house is for all classes, men and women alike': women, leisure and drink in Second World War England, Women's History Review 12: 423-443.

Langhamer, C. (2000) Women's Leisure in England, 1920-60. Manchester: Manchester University Press.

Lawson, J. (2011) Chronotope, story, and historical geography: Mikhail Bakhtin and the space-time of narratives, Antipode 43: 384-412.

Liu, C.H.C. (1998) Folding the time-space continuum: Atwood's Cat's Eye as chronotopic bildungsroman, in Tötösy de Zepetnek, S. and Leung, Y-n. (eds) Canadian Literature and Culture and a Taiwan Perspective. Alberta: Research Institute for Comparative Literature, pp. 237-48.

Lodge, D. (1990) After Bakhtin: Essays on Fiction and Criticism. London: Routledge.

Miller, J.H. (1995) Topographies. Stanford, CA: Stanford University Press.

Moretti, F. (2013) The Bourgeois: Between History and Literature. London: Verso.

Morson, G.S. (1991) Bakhtin, genres, and temporality, New Literary History 22: 1071-1092.

Morson, G.S. and Emerson, C. (1990) Mikhail Bakhtin: Creation of a Prosaics. Stanford, CA: Stanford University Press.

Moss, S. (2009) 'A grave question': the Children Act and Public House regulation, c. 1908-1939’, Crimes and Misdemeanours 3: 98-117.

Mulíček, O., Osman, R. and Seidenglanz, D. (2014) Urban rhythms: a chronotopic approach to urban timescape, Time and Society (pre-print publication)

Painter, J. (2006) Prosaic geographies of stateness, Political Geography 25: 752-774.

Palmer, A. (2004) Fictional Minds. Lincoln, NE: University of Nebraska Press.

Reed, W.L. (2014) Romantic Literature in Light of Bakhtin. London: Bloomsbury.

Ricoeur, P. (1988) Time and Narrative, Volume 3. Translated by K. McLaughlin and D. Pellauer. Chicago: University of Chicago Press.

Steinby, L. (2013) Bakhtin's concept of the chronotope: the viewpoint of an acting subject, in Steinby, L. and Klapuri, T. (eds) Bakhtin and his Others: (Inter)subjectivity, Chronotope, Dialogism. London: Anthem Press, pp. 105125.

Sui, D. (2012) Looking through Hägerstrand's dual vistas: towards a unifying framework for time geography, Journal of Transport Geography 23: 5-16. 
Valverde, M. (2003) Law's Dream of a Common Knowledge. Princeton: Princeton University Press.

Valverde, M. (2015) Chronotopes of Law: Jurisdiction, Scale and Governance. New York: Routledge.

Vice, S. (1997) Introducing Bakhtin. Manchester: Manchester University Press.

Widdowson, P.J. (1978) The saloon bar society: Patrick Hamilton's fiction in the 1930s, in Lucas, J. (ed) The 1930s: A Challenge to Orthodoxy, 117-137. Hassocks, Sussex: Harvester Press.

Zunshine, L. (2006) Why We Read Fiction: Theory of Mind and the Novel. Columbus, $\mathrm{OH}$ : Ohio State University Press. 